\title{
Criticism of Istanbul inner city urban transportation from the perspective of urban form
}

\author{
E. Aktuglu Aktan \\ Department of City and Regional Planning, \\ Yuldız Technical University, Turkey
}

\begin{abstract}
Economic and social changes are key factors of urbanization in developing countries. Urban mobility (transportation), which developed to satisfy certain needs, grew as an issue while urban areas expanded and populations increased parallel to urban expansion which was reflected to urbanization. A higher weight of road usage for urban (inner city) transportation has worrying results, especially in populated and widespread cities. Actions taken to support road development is exhausting nature and transforming it into an artificial environment. This situation, which is a consequence of uncontrolled development of urban macroform, along with underdeveloped city transportation technology, creates problems such as population-accessibility, sprawling of the city (without any step changes), insufficient mass-transport and time-location relation dependency on distance.

The objective of this article is to explain how the urban form of Istanbul became unlivable, unperceivable and unsustainable, while the city converted from a pedestrian and waterfront city to an automobile and land-based city. Inner city transportation in Istanbul is mainly solved through roads, which causes worrying results regarding urban form. One result is the urban growth towards the natural resources residing at the north of the city. Transformation to a pedestrian city, which is integrated to a mass-transport system, is the remedy to stop this growth. This problem can be solved by strategic decisions taken within an integrated approach. In this article, the problem is investigated within urban form - urban (inner city) transportation relation and a solution is sought with a strategic approach.
\end{abstract}

Keywords: urban transport, urban form, city planning, Istanbul. 


\section{Introduction}

Increasing populations, urbanization, the period of industrialization and uncontrolled resource usage cause negative results for living areas. Nature is transformed by spreading developed areas into an artificial environment. We have to utilize technology, information and other facilities of our modern age for our own good.

In this paper, inner city transportation problems are explained with urban form related to sustainability. Planning and transportation subjects must be together and should not be thought of separately. It is said that transportation and urban form affect each other.

Population movements, migration, economy, social structure, politics, environment, technology and natural disasters are the main factors that affect urban form development (fig. 1). Although there is no given prioritization to these factors, transportation is accepted as having a substantial role.

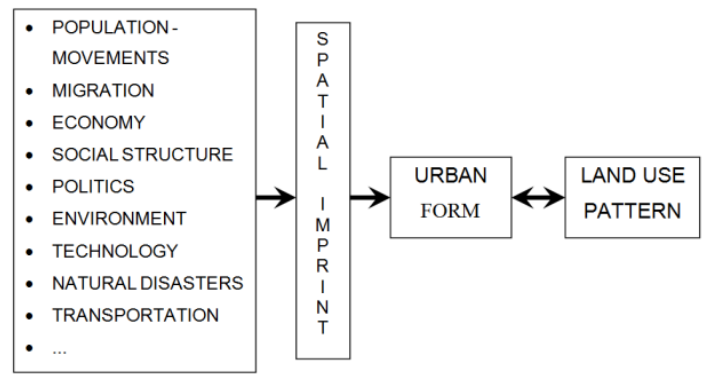

Figure 1: $\quad$ Urban form development.

The transportation system must be firstly for people, rather than for goods, services or other uses. The transportation system must be a part of the city. Over a period of time there has been a development from being a pedestrian (scale) city to one of being a sprawled, unperceivable, inaccessible city. It can be said that one of the most important reason for this negative situation is the automobile.

When we look at the inner city transportation, as long as settlements stay in the zone of a pedestrian accessible area, transportation is not a problem. When settlement zones pass the limits of pedestrian scale, transportation starts to become a problem in cities.

In this paper, after discussing the approaches for urban form and its components with sustainable urban form, İstanbul's urban forming is examined in terms of transportation and new strategic ideas are explained for İstanbul's transportation problem.

\section{Urban form}

Form and shape are areas or masses which define objects in space. Architectural form is the contact point between space and mass. Architectural forms, patterns, 
structures, light and shadow, grade, and color come together to give the feeling of the quality of the space's form. The designer forms this feeling not only by using both the interior and exterior space of the building, but also by relating these places to each other.

If we describe 'physical form', physical dimensions should be organized together to turn out some functions to be true. This organization enables variety in the solution.

A city's 'physical form', on the other hand, is formed by the components of geographic and historical effects. Economical, social and cultural events are also parts of these components. To talk about a city's form, we need to describe a city in terms of its components.

Spreiregen describes these components as follows:

A city is generally thought of in terms of 'size' - its population and physical extent. Size is closely linked to 'shape' - the physical outline in horizontal plan form and vertical profile or contour. Size and shape are qualified by 'pattern' - the underlying geometry of city form. Size, shape and pattern are further modified by 'density' - the intensity of use of land by people and buildings. Density is determined by urban 'texture' and 'grain' - the degree of homogeneity or heterogeneity of use by people or buildings [1].

\section{Urban form for sustainable transportation}

The change in life style and transportation technology has started to change the urban form. The transportation first started with public transportation and later the number of individual transportation increased, so this change caused a big problem especially in big cities.

While transportation technology started to develop in the way of being faster, cleverer, and with a higher capacity, it is based on transportation vehicles, and city forms have spread as there are no limits. Traffic is an important element that limits the personal relations. For this reason, each activity that reduces vehicle traffic can affect city life positively.

Ecological city models are the cities that have compact city forms and cities that are sufficient in themselves. Self-sufficient cities are the part of ideal green cities. The purpose of this type of city is to protect natural resources and design these cities with nature in the best form. For the sustainability of this ecological system, ecological knowledge should be enhanced, so the consumption of natural resources can decrease. This ecological model tries to perform economical and environmental functions in itself with its own dynamics. The compact city form is the other type of ecological city model. In this type of city, the cities are designed as more compact, the buildings have a bigger population density, the buildings have mixed-use structures and there is less energy consumption. This city model, when compared with the previous one, has less natural zones and it is human-centered. The purpose of this city model is to reduce the negative effects of city life and negative outside effects.

In a compact city model, the quality of public transportation and the satisfaction of pedestrians increase, while personal automobile usage decreases. 
The activities generally take place around the public transportation stoppingplaces and the intensity of people decrease when these places increase in number. London can be a good example for this situation. In a compact city life, fast speed transportation system links one centre of neighborhood to another centre of neighborhood. With the decrease of automobile usage, walking and cycling are preferred more [2].

As a result, city compact structure and neighborhood centre's accessibility to public transportation system support each other. By setting some limitations and charging a fee for personal automobiles, public transportation for the long distances and pedestrian circulation for the short distances can be encouraged. So, the system will start working.

The development of a city should be a way of joining districts which are limited with human scale. In this way, available cities may be changed into walkable forms. Public transportation must be the priority in the mobility of districts which are formed in a way of joining the neighborhoods.

To encourage pedestrian and cycling circulation, cities' districts must be organized according to pedestrian scale. Pedestrian and cycling must be encouraged by putting some limits for the usage of automobiles. This situation is also important for sustainability. The optimum neighborhood is discussed in Figure 2. In this figure it is shown how 7500 people are directed to which transportation in different city scales and density.

In Figure 2A, as the walking distance of a person is calculated as $500 \mathrm{~m}$ maximum, the areas which are over $500 \mathrm{~m}$ from the centre consist of $59 \%$ of the whole area. In this situation, the numbers of people who use buses or railway
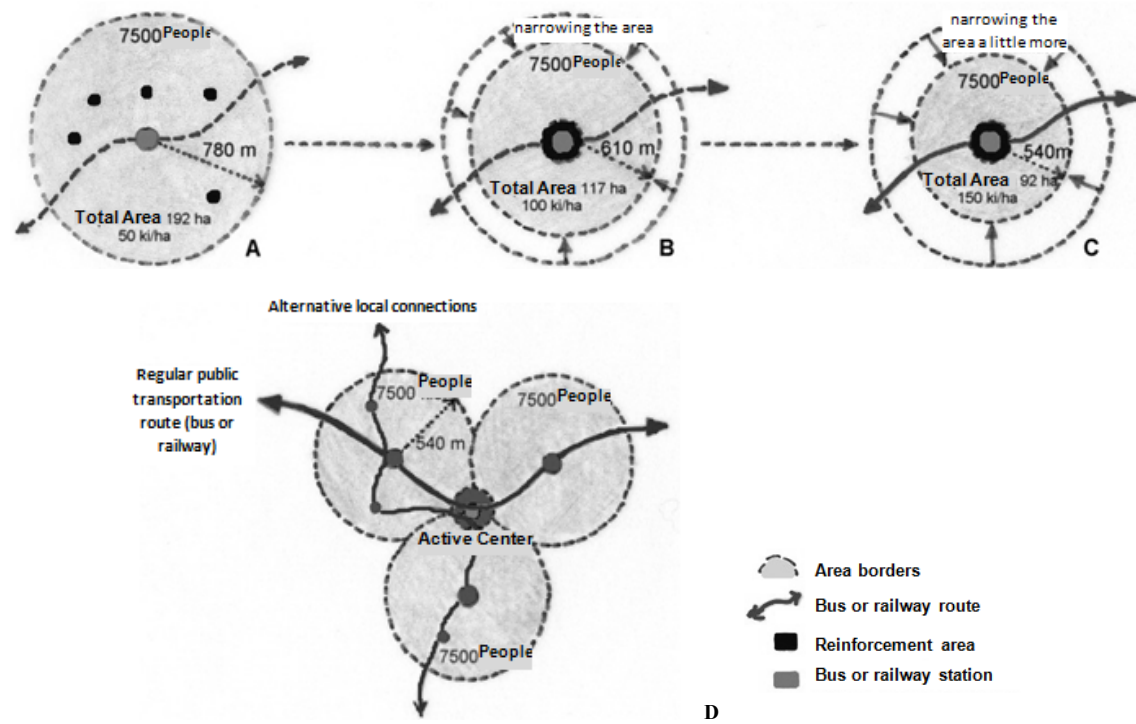

Figure 2: The forming of neighborhood according to the public transportation system (interpretation of $[3$, p.61]). 
system are less since the distance to public transportation is over the standard walking distance. Automobiles are encouraged in this situation.

In Figure 2B, the areas which are over $500 \mathrm{~m}$ from centre consist of $31 \%$ of the whole the area. In this situation, the number of people who use buses and railway system are limited. Automobiles are needed for local trips.

In Figure 2C, the areas which are over $500 \mathrm{~m}$ from centre consist $13 \%$ of the whole area. The density of the neighborhood looks more compact in Figure C.

In Figure 2D, the network of public local links and the joining of neighborhoods are shown.

It is important that a relationship between density and design for useful transportation is need. The message is clear: the lower the density, the larger the amount of area that is occupied by buildings, roads and open space. A hypothetical low density neighborhood could extend to nearly 1.5 kilometers in diameter, pushing over $60 \%$ of the houses beyond the acceptable 500 -meter or five-minute walking limit. This form of layout promotes excessive car use and makes it difficult to justify a bus route. As density levels are increased - even to the moderate levels of 100 or 150 people per hectare - the land-take diminishes rapidly. More people are close enough to communal facilities to walk, and an efficient bus service can be made viable. Moreover, the critical mass of development contributes to the informal vitality of the streets and public places that attracts people to city centers and urban neighborhoods, as well as contributing to energy efficiency [3, p.60].

\section{Urban form development in Istanbul}

Istanbul is located in the Marmara Region at the northwestern part of Turkey. The older part of the city is in Europe, the other part in Asia. 15\% of the whole population of Turkey lives in Istanbul. This, of course, brings crowdedness and other problems waiting for urgent solutions.

Population growth rate in Istanbul increased dramatically after 1960s due to the migration from rural parts of the country and urbanization effect. Between 1927 and 1960 the population almost doubled but from 1960 onward it increased approximately by four fold.

It is clear to explain the urban form of development of İstanbul with the development of the transportation system of İstanbul.

\subsection{The active development of pedestrian and seaway}

Until the 17th century the capital of the Ottoman Empire consisted of three main regions: Istanbul, Galata, to the north of Haliç and Üsküdar. These districts are separated from each other by waterways. Istanbul was the nucleus of the settlement and is at the south of Halic. Galata, which is across Haliç, and Üsküdar, which is on the Asian side of Bosphorus, were the main suburbs. The radius of the city was only $3 \mathrm{~km}$, pedestrian scale.

In the 18th century there was a focal settlement form in large houses among nice gardens and groves of the Asian side. There was also a non-linear settlement 
form in the European side, where people from various socioeconomic levels lived.

Rowboats were the most important transportation vehicles until the early 1900s.

In the 19th century, with the new developments in transportation systems and technologies, (tramways, sea transport) summer residences along the Bosphorus started to be used as regular residences.

In that period, the development of docks and its surrounds was related to the walking distance. Because of this scale, there were empty areas, especially between Bosphorus villages (fig. 3). These villages were only served with seaways as they couldn't be improved because of physical limits and limited land transportation. For this reason, these villages have closed systems.

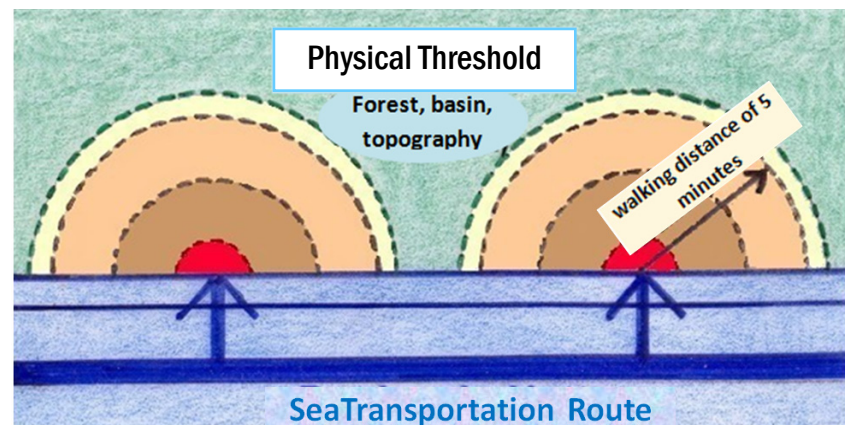

Figure 3: The urban form development along the Bosphorus interms of sea transport system [4, p.184].
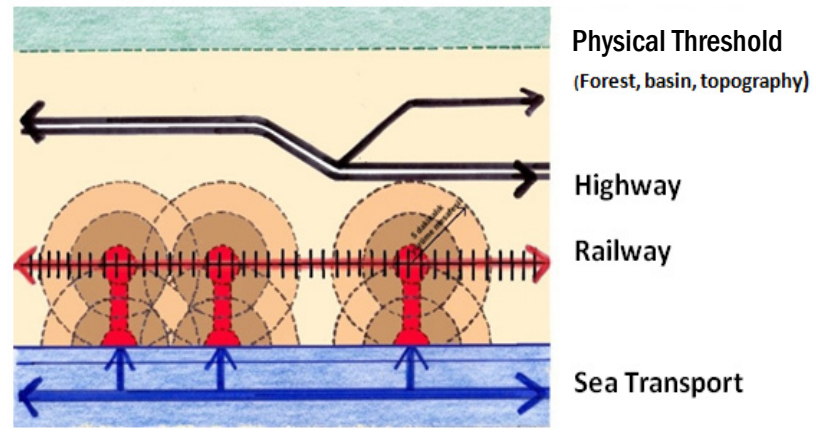

Figure 4: The urban form development along the Marmara shore in terms of railway transport system [4, p.184].

\subsection{Development with sea transport, railway system factor}

In railway systems, like in the tram period, the neighborhoods are scaled as pedestrian zones. The settlements appear around the stations. The important point is the distance between stations. When the distances between stations are 
more than walking distance (fig. 4), empty areas appear between neighborhoods as in the docks.

\subsection{Development with highway factor}

Since the 1950s, transportation policies favoured motorways and neglected more economic systems such as railways and sea transport.

When the automobile system begins in a settlement the whole pedestrian system changes. The city disperses by the automobile's accessibility (fig. 5).

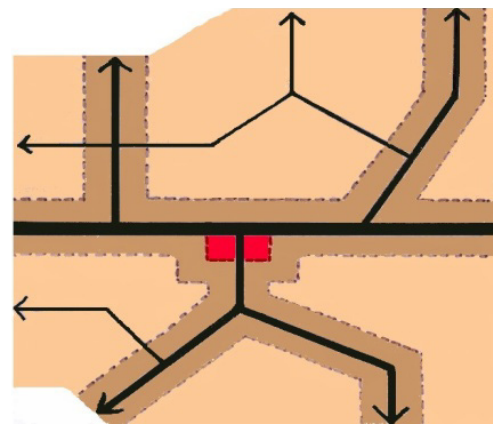

Figure 5: $\quad$ Urban development with highway system [4, p.185].

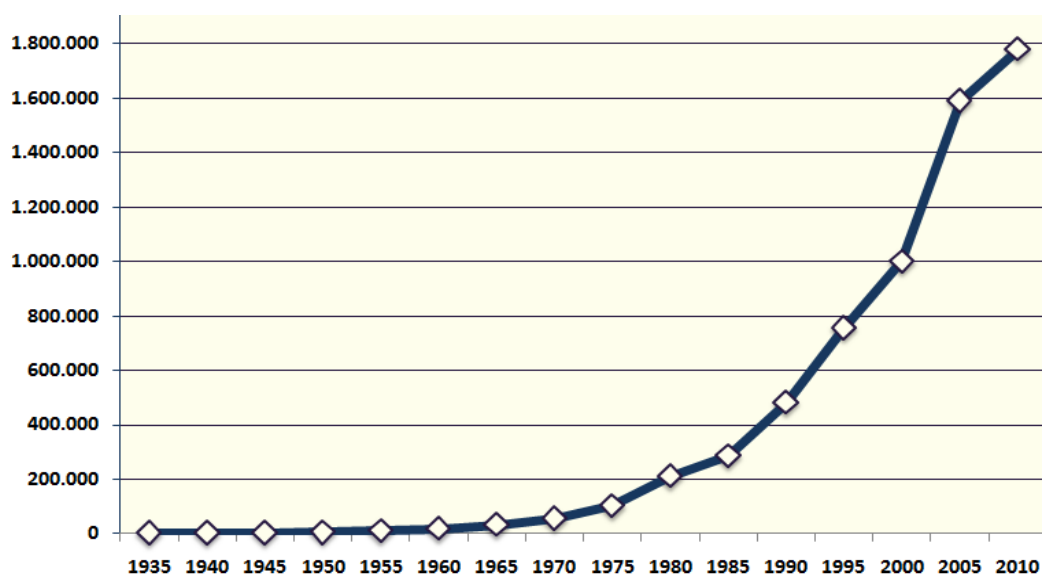

Figure 6: Change in the number of registered private automobiles (1935-2010).

This formation changes the natural and constructed environment rapidly also messing the vital regulations composed of both sea transport and railway system.

The urban pattern with empty spots which was obtained in the early stages of metropolitan development could not be protected. With the effect of legal and illegal land allotments the city became a giant industrial city. It sprawled and grew in all dimensions. After the invention of the automobile new roads in 
Istanbul were constructed. Roads formed for pedestrians were not appropriate for cars. Frequent fires also helped this transformation. In 1960's, the removal of tram lines, supporting automobiles by road constructions and building Bosphorus Bridges were presented as solutions.

Two bridges constructed across the Bosphorus in 1973 and 1988 did not only change the urban form of Istanbul but also triggered a rapid and dense transformation period in Bosphorus. Bridges and peripheral transit ways encouraged car ownership and accelerated decentralization. The city headed towards the land areas and districts away from the sea started to grow.

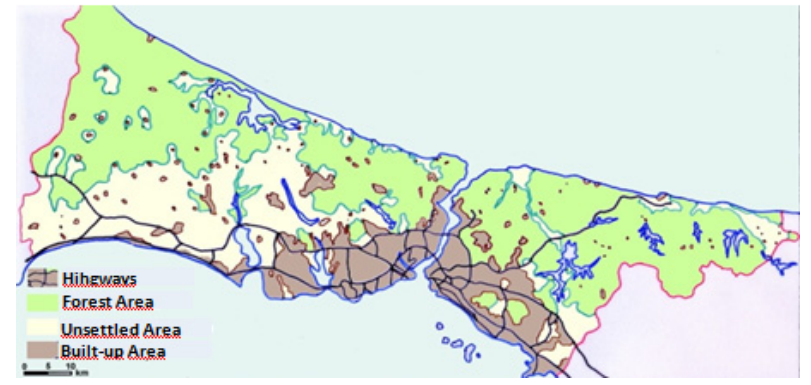

Figure 7: $\quad$ İstanbul in 2000 with built up areas and forest areas [4, p.186].

After the construction of Fatih Sultan Mehmet Bridge, especially in the Asian side around bridge junctions, mainly in Beylerbeyi and surroundings, unplanned settlements grew. Moreover, the city started to grow towards the north. The growth towards the north along Bosphorus should be restricted, because vital natural resources such as forests and water supplies are located in that region. The City's tendency of growth spreading to the north side of İstanbul is a viable threat in terms of the city's sustainability. Some outcomes are seen when the transportation system development of Istanbul and current residential areas (fig. 8) are superposed. Coastal settlements which were formed by the sea transport, were disconnected from each other and were big enough to be self-sufficient whereas the railway system promoted the city to grow as bands parallel to the sea. The changing process starting with automobility has led to a completely different result: without any space and, despite the physical thresholds. Although it is thought that the second bridge and freeway junctions should bound the residential areas, the freeway routes stimulates structuring by effecting areas in both directions. Also, the little villages placed on the northern part of TEM (in the forest area) which have potentially to grow and to be the areas which the city can escape to, should be supported with new transportation systems.

Nowadays, a third bridge construction over the Bosphorus and Istanbul forest area is proposed. However, the forests, drinking water supplies, and agricultural areas located at the north of the second bridge are vital resources of Istanbul.

With the Marmaray Project which started off in May 2004, it is planned to connect the two continents by railways. However, this project did not end the discussions on the possibility of constructing a 3rd bridge over the Bosphorus. Unfortunately, the project has begun but the discussions are still heated. 


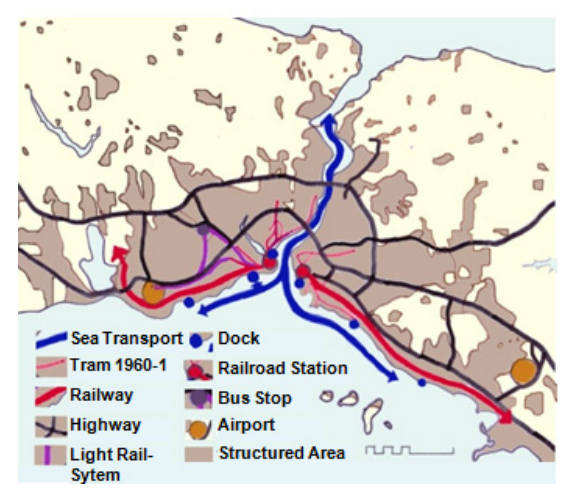

Figure 8: Istanbul's transportation system in the process with the current format $[4, \mathrm{p} .186]$.

The radius of the city is now $75-100 \mathrm{~km}$. In 170 years Istanbul has grown into a metropolitan with more than 12 million inhabitants. There exits various mass transport systems through the city and private cars are one of the main means of transport nowadays. Istanbul which used to be a ports and docks city rapidly became an industrial and cultural land city and transformation from pedestrian and rowboats to public transport took place synchronously.

\section{Strategic proposal}

The planning concept aimed at sustainability of human life, and even all living creatures, should basically ensure the resources for living. However, these living resources are consumed rapidly because of the cursory approaches of the authorities in Istanbul (instantaneous solutions), zoning remissions and transport policy focusing mostly on the highways.

Today, as a result of the insufficiency of the current public transport system (sea transport and railway), Istanbul is facing serious transport problems. More concentration on the public transport systems and re-evaluation of the urban form should be in this direction.

Considering the city's size and spread, the metric distance is not a problem and the temporal distances should be emphasized. For this, rapid and express public transport systems need to be adapted to Istanbul. Construction of the railway systems (metro, Marmaray...) is very important. However, the metro currently serves a limited area only. On one hand, the subway network should be expanded, while using more advanced technology, faster rail systems should be considered for the inner city and infrastructure of the city should be established in the network form. Achieving integration and synchronization of the transport system in different modes has positive impacts on urban development, and carries the city into the future. Coordination between public transport systems should be provided. 
The areas outside the zones of influence of the stops must be minimized, according to the pedestrian access distance. If pedestrian approach to public transport is under control, car usage intensity will decrease in the urban part.

The city, when it has reached a certain size, cannot be accessed, is not detectable, is uninhabitable. However, in such situations intervention should be made for the city's future in the context of form. The city's transformation to a hollow structure and growth with a jump should be discussed. In order to establish these, transportation systems should be changed.

\subsection{Transportation based future scenario for Istanbul's macroform}

In this paper, for the urban transport format, a city form oriented urban transportation based strategic plan approach scenario for Istanbul is proposed. This scenario is not a direct approach to the plan. This issue should be addressed through a holistic approach.

The tendency of Istanbul's city form to develop is defined as a vital problem. In this concept, interaction of city form and urban transportation in the city is reduced to the same sample area with the problem of Istanbul having livable, sustainable conditions. During the developmental process, separation of planning decisions and transportation decisions have created today's Istanbul. Turning into an institution is required in the act of planning. The aim, objective, strategy for the city for everyone, even including executives, must be in the same direction, it should be constructed and should be applied; the principles the party or parties should not be changed by the party or parties.

İstanbul is a large city to walk, but in the future it should become a city that is easy to walk in. In terms of defined sub-areas (certain sizes), if the necessary conditions are provided, walking could be a part of the whole system. The areas that will be subject to transformation, renovation, etc should primarily be planned accordingly. Developing a safe, attractive and attainable environment will improve the walking experience of Istanbul citizens. Several institutions should encourage and advertise about this subject.

What is to be accentuated in public transportation should be human beings. A "human oriented transportation system" could be achieved primarily by strengthening the pedestrian transport. Cities are for people, they should not be for vehicles. It is very hard to take back the habit of using vehicles even for walking distance transports and the increase in demand related to this.

In order to fix the existing poor structure and establish an environment friendly, sustainable transport system that will prioritize human beings; planning, auditing and managing should be applied at first for pedestrianising, and then for improving the public transport.

While talking about pedestrian transportation in Istanbul, people leaving their cars completely and going everywhere on foot is not mentioned. However, people in Istanbul have to go by car to many places because actually there is no way to walk most of the time.

Arrangements should be made aiming to encourage people to walk in the city. Applications considering optimum walking distances will reduce car usage. For example, stop intervals of the metro (subway) running between the Taksim- 
Levent 4, being almost twice the size of London or Paris when compared, is remarkable. If the Istanbul metro system is associated with pedestrian circulation there would be more stops on the line. In that case, there would not be any need of public transportation other than a subway system or using private vehicles.

After this stage, the groups that plan the city of Istanbul, or just a part of it, will pass to substages aiming at regional and area properties in line with the main strategy. Substages go down to pedestrian access distance of a neighborhood group. This approach contains many professions and act groups as the transportation planning, transportation engineering, land use planning, urban design, landscape architecture, tourism, health, socialization, crime prevention, grouping community enhancement within.

Istanbul can turn into a livable city in the future if the urban structure will develop according to the proposed applications from now on. For this;

- Access to walking, cycling and public transport should be suitable for Istanbul and at the same time a city form having compactness encouraging social effects (the need for public space) should be adopted.

- Approach to the strategic plan for the city of Istanbul in the context of the city form-transport relationship; suggestions that are compact, multicentered, sustainable, mixed use preferred and walking focused, public transport based, agreed with urban uses or directing the uses, should be considered for the strategic plan approach of Istanbul.

- It is being considered that an established system will be formed by the changes in the city form within the context of sub-zones being compact and mixed-use preferred, multi-centered, having a sustainable planning approach that is prescribed for Istanbul's city form as "a strategic planned approach of walking focused and mainly usage of public transportation". This change will require a long time especially for all of the city. This strategic approach can reach its goal only if it is adopted by all relevant institutions with the accepting the need in the case of the city's future. The occurring changes in line with the strategy will be reflected to the whole city, being a positive example for other regions as encouragements.

Tending to walk, provides potential benefit on the health, environmental and economic issues. The first goal of walking and public transport-oriented strategic plan approach is mainly to make people choose walking for short journeys primarily, and choosing a mixture of walking and public transport for long journeys. In order to increase the access as pedestrians in the city, create highly qualified urban environment and revitalize the public areas, the city should be formatted in a planned and targeted approach in time.

The size of a city's sub-zones should be established according to the distance that a pedestrian can walk. People, living in a sub-zone, will meet their primary (daily) needs in their close neighborhood. In short, reinforcement areas should be created figuring out the pedestrian access. The station of the public transport system (sea transport or railway) that provides to pass to another sub-zone will be located to the most appropriate place (can be the center) of the sub-zone. 


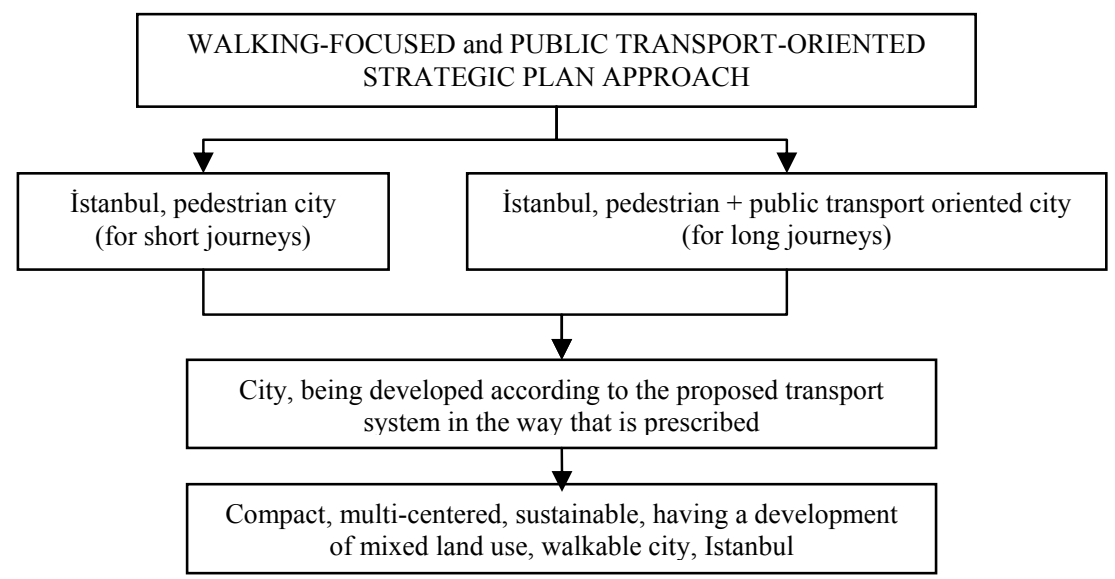

Figure 9: A proposal; walking-oriented strategic plan approach for Istanbul, $([4, \mathrm{p} .196])$.

The main theme is to create a walkable-Istanbul. In order to solve the interactions of residential-office, residential-school, residential-shopping, etc. without requiring private car driving, in a comfortable way, by examining the context by time and distance and mainly with pedestrian or public transport system, city form should be compact, multi-centered, having a development of mixed-land usage and must be sustainable.

The change should be announced to the public so people are updated. The safety matter is considerably important for pedestrians. Lighting, visibility, limited allowance for vehicle traffic and the traffic controls are the important topics. With the walking schemes (information boards), the public people will learn about Istanbul on foot. In a sustainable city, transportation can be so easy as driving a car if safe walking paths and cycling are supplied. Special locations in the city should be joined together. An urban regeneration and regulation based on creation and management of highly qualified public places is prescribed. Public living assisted walking is a way of life that is trying to be re-enforced in the cities in recent years. A gradual increase is seen in walking and other pedestrian-oriented action area volumes in the urban areas that is planned in this direction. All of the institutions should act consistently as what was mentioned above for this planning approach that takes the needs of pedestrians into consideration.

In order not to face any transportation problems during the urban development process, preparation of a transportation plan compatible with the master plans prepared in accordance with the needs of cities is a condition that must be considered primarily. In order for the city to develop in a healthy way, the interactions of environment and land use with transportation should be planned.

The relationship of the proposed transportation system, the residential area size and the form for Istanbul is shown in Figure 10. Here, it draws attention to 


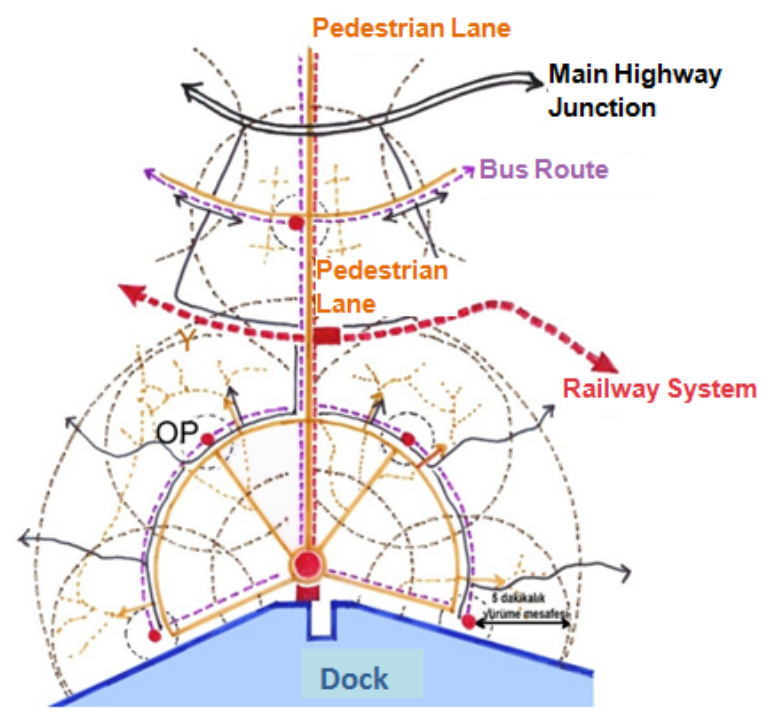

Figure 10: The alternative development scheme of city form-transport relationship along the coast for Istanbul, ([3, p.92] interpreted for Istanbul by E. Aktan).

the walking distance to reach the transportation systems. Priority for transport system is sea transport and railway system. Highway transport is the third and the last choice. Although the highway connections are not dominant, parking places and areas serving public transportation should be established in subregion centers.

City planners obviously cannot accept a future city concept based on utopia. However, new thoughts and projects about future cities - even if they are fantastic - encourage creative thinking and contribute to city planning as long as those thoughts and projects are attempts to dream of social and cultural development.

\section{References}

[1] Spreiregen, P. D., The Architecture of Towns and Cities, McGraw-Hill, USA, p. 64, 1965.

[2] Rogers, R., ve Gumuchdjian, P., (1997), Cities for a Small Planet, Faber \& Faber, London, p. 40, 1997.

[3] Rogers, R., Towards an Urban Renaissace, the Urban Task Force, E\&FN Spon, UK, 1999.

[4] Aktuğlu Aktan, E. Ö., Kent Biçimi-Ulaşım Etkileşimine İlişkin (Tarihsel ve Güncel) Yaklaşımlar ve Istanbul Örneği, YTÜ FBE Şehir ve Bölge Planlama Anabilim Dalı Şehir Planlama Programı Yayınlanmamış Doktora Tezi, PhD Thesis, İstanbul, 2006. 